\title{
Projetos de ensino e de aprendizagem multidisciplinares: relato e análise de propostas
}

\author{
Letícia Savaris*, Maria Teresa Ceron Trevisol**, Márcia Salete Bomm Lazzarin*** \\ *Mestranda em Educação, UNOESC ** Doutora em Psicologia pelo Instituto de Psicologia da USP. Docente da \\ graduação e do Programa de Pós-graduação em Educação da UNOESC, ***Mestranda em Educação, UNOESC \\ Brasil
}

\begin{abstract}
Resumo
A fragmentação do conhecimento fragilizou as relações entre as áreas do saber, mas o emergir da complexidade favoreceu o estabelecimento dessas relações. Considerando que este trabalho encontrase em desenvolvimento e vincula-se ao Projeto do Observatório da Educação intitulado "Estratégias e ações multidisciplinares nas áreas de conhecimentos das ciências humanas, ciências da natureza e linguagens, na mesorregião do oeste catarinense: implicações na qualidade da educação básica”, pretende-se analisar se uma das escolas participantes desse Projeto tem efetuado, está efetuando ou planejando projetos de ensino e de aprendizagem multi, trans ou interdisciplinares e em que medida contribuem na efetivação de uma aprendizagem significativa.
\end{abstract}

Palabras clave: ensino, aprendizagem, conhecimento, diálogo.

Processos de ensino e de aprendizagem multi, trans e interdisciplinares: o desafio de romper com a fragmentação do conhecimento

A fragmentação dos saberes nos processos de ensino e de aprendizagem de algumas instituições escolares brasileiras tornou-se alvo de reflexões e questionamentos, tanto no meio escolar quanto em pesquisas científicas. Por isso, nesse cenário, torna-se interessante repensar acerca do ponto a que se chegou o distanciamento das disciplinas, bem como a compartimentalização do ser humano, para com isso verificar meios que possibilitem a interação e integração dos saberes e do ser humano, ou seja, que estabeleçam diálogos e relações entre os mesmos.

Entre os séculos XVII e XIX, com o surgimento da ciência moderna, do Iluminismo e da Revolução Industrial, ocorreu uma intensa fragmentação disciplinar. Augusto Comte, nesse mesmo período, apoiando-se no positivismo e no desenvolvimento industrial da sociedade, organizou as ciências em hierarquias (SOMMERMAN, 2005), da mesma forma que o princípio da fragmentação de Descartes (1973), citado por Morin (2003), considera que devido à complexidade de um fenômeno, tornava-se relevante "divisar cada uma das dificuldades [...] em tantas parcelas quantas possíveis e quantas necessárias fossem para melhor resolvê-la".

Logo após, especificamente na metade do século XX, a fragmentação intensa resultou na hiperespecialização do saber, refletindo no currículo das instituições escolares, onde se encontram organizados por disciplinas e ministrados por especialistas de diferentes áreas. Sobre a hiperespecialização, Morin (2003) cita que a mesma "[...] impede de ver o global (que ela fragmenta em parcelas), bem como o essencial (que ela dilui)”. Ele ainda menciona que os desenvolvimentos disciplinares das ciências “[...] não só trouxeram as vantagens da divisão do trabalho, mas também os inconvenientes da superespecialização, do confinamento e do despedaçamento do saber. Não só produziram o conhecimento e a elucidação, mas também a ignorância e a cegueira” (MORIN, 2003).

Podemos observar, então, que a disciplinaridade, sozinha e isolada, não é mais capaz de resolver e explanar os fenômenos decorrentes na sociedade, tendo em vista a complexidade que a circunda. Dessa forma, emergem diferentes meios e possibilidades de combinação e articulação dos conhecimentos a fim de explicar esses fenômenos complexos, via multidisciplinaridade, interdisciplinaridade e transdisciplinaridade.

A multidisciplinaridade refere-se à justaposição das disciplinas, mantendo cada uma sua integridade e seu individualismo, além de não estabelecer relações com outros saberes. Em outras palavras, Sommerman (2005) cita que a multidisciplinaridade "na prática pedagógica, é a organização mais comum do conhecimento, onde as matérias e as disciplinas se apresentam de maneira independente, sem explicitar as relações entre elas [...]”.

Mais além da multidisciplinaridade, a interdisciplinaridade diz respeito a um enfoque científico e pedagógico, no qual as disciplinas se entrecruzam, se relacionam, dialogam entre si e entre os

A pesquisa está vinculada ao Projeto do Observatório da Educação "Estratégias e ações multidisciplinares nas áreas de conhecimentos das ciências humanas, ciências da natureza e linguagens, na mesorregião do oeste catarinense: implicações na qualidade da educação básica”. Edital Capes ${ }^{\circ}$ 049/2012.

Correspondencia: Letícia Savaris, letisavaris@hotmail.com

Selección y y peer-review bajo responsabilidad del Grupo de Investigación G000422-GIPDAE, Universidade da Coruña, España 
sujeitos envolvidos na produção dos saberes, instaurando, dessa forma, um espírito colaborativo. Não se exclui as disciplinas, mas se respeitam as mesmas. Para isso, é preciso dispor da condição de humildade, da abertura para o outro, de ouvir o que o outro tem a dizer, de ser sensível e, principalmente, de conversar. Para Lück (2013):

Interdisciplinaridade é o processo que envolve a integração e o engajamento de educadores, num trabalho conjunto, de interação das disciplinas do currículo escolar entre si e com a realidade, de modo a superar a fragmentação do ensino, objetivando a formação integral dos alunos, a fim de que possam exercer criticamente a cidadania, mediante uma visão global de mundo e serem capazes de enfrentar os problemas complexos, amplos e globais da realidade atual.

E a transdisciplinaridade, segundo Follmann (2005) é "fruto de toda uma corrente de preocupações voltadas contra a fragmentação do saber [...] que traz novos elementos decisivos para o avanço do conhecimento".

Frisa-se que toda e qualquer tentativa e ação interdisciplinar ou transdisciplinar requer a quebra do paradigma newtoniano-cartesiano, o qual baseia-se na racionalidade, na dedução, no dualismo, na fragmentação, nas especialidades, no individualismo, não considerando o conhecimento e o ser humano em sua totalidade, em sua multidimensionalidade e multirreferencialidade.

Segundo Santos (2009), a efetivação de uma mudança epistemológica requer uma mudança atitudinal. Sendo assim, torna-se importante caracterizar tal mudança enquanto processo que poderá ocorrer de maneira gradual, ou seja, como menciona Morin (2003), “[...] a iniciativa só pode partir de uma minoria, a princípio incompreendida, às vezes perseguida. Depois, a ideia é disseminada e, quando se difunde, torna-se uma força atuante".

Desse modo, tendo em vista o emergir de algumas inquietações acerca do cenário enfatizado anteriormente, bem como de minha vinculação ao Projeto de Pesquisa do Observatório da Educação denominado "Estratégias e ações multidisciplinares nas áreas de conhecimentos das ciências humanas, ciências da natureza e linguagens, na mesorregião do oeste catarinense: implicações na qualidade da educação básica”, organizou-se o trabalho de investigação abordando a temática: "Projetos de ensino e de aprendizagem multidisciplinares: relato e análise de propostas".

Vale ressaltar que, como esta pesquisa encontra-se em curso, algumas modificações estão sendo realizadas, considerando o prazo para o período de qualificação.

Objetiva-se, então, verificar se a escola pública municipal localizada em Concórdia está efetuando, tem efetuado ou encontra-se em planejamento, projetos de ensino e de aprendizagem multi, trans ou interdisciplinares, particularmente no ensino fundamental, considerando o período de 2009 a 2014, e em que medida estes projetos contribuem na efetivação de uma aprendizagem significativa.

E, no que se refere aos objetivos específicos da pesquisa elencou-se: i) verificar nos projetos de ensino e de aprendizagem multi, trans ou interdisciplinares desenvolvidos no ensino fundamental da escola pública municipal de Concórdia: a finalidade de sua organização, os sujeitos participantes, o período de realização, a metodologia utilizada, as principais atividades desenvolvidas e a avaliação dos mesmos; e, ii) identificar dilemas, dificuldades ou obstáculos que os participantes do percurso de planejamento e de execução do projeto de ensino e de aprendizagem multi, trans e interdisciplinares, da Escola de Concórdia, selecionada para constituir foco de observação e análise desta pesquisa, evidenciam neste percurso.

\section{Método}

Consiste em uma pesquisa descritiva, de cunho exploratório e de natureza qualitativa. A pesquisa descritiva objetiva descrever as características de uma população ou fenômeno ou estabelecer relações entre variáveis (GIL, 2002, p. 28).

O estudo exploratório, segundo Gil (2002) citado por Strieder (2009), “[...] tem como meta proporcionar maior familiaridade com o problema, visando torná-lo explícito ou possibilitar a construção de hipóteses. Ela envolve levantamento bibliográfico, entrevista com pessoas que tiveram experiências práticas com o problema proposto ou a análise de exemplos que estimulem a compreensão".

Dessa forma, essa metodologia se adequa ao que se pretende investigar, dando conta de todos os objetivos.

\section{Participantes}

Inicialmente participaram da pesquisa cinco profissionais da educação das doze escolas públicas municipais participantes do Projeto do Observatório da Educação, sendo três professores(as), um diretor (a) e um coordenador(a) pedagógico(a), porém atualmente realizou-se um recorte da amostra, selecionando-se somente uma das escolas, esta localizada em Concórdia - Santa Catarina, Brasil, para efetuar a análise dos dados.

Constituíram a amostra da pesquisa um total de 44 sujeitos, que compreendem tanto diretores, quanto coordenadores e professores.

O director foi identificado como D1, a coordenadora pedagógica como C1 e as professoras P1, P2 e P3.

\section{Instrumentos para coleta de dados}

Os instrumentos utilizados para a coleta de dados foram, inicialmente para as escolas que constituíram a amostra desta investigação, um questionário composto por questões abertas e fechadas. E, no acompanhamento da Escola de Concórdia, também, efetuou-se a observação e coleta de registros (atividades 
desenvolvidas, fotografias, entre outros) por meio de observação in loco.

De modo resumido, realizou-se, até então, as seguintes etapas da pesquisa:

Etapa 1: Aplicação de um estudo piloto com uma profissional da educação, objetivando avaliar se as questões que compõem o instrumento de coleta de dados serão entendidas pelos sujeitos da pesquisa

Etapa 2: Envio do projeto de pesquisa ao Comitê de Ética em Pesquisa (CEP/UNOESC), aprovado pelo Parecer Consubstanciado 749.282 em treze de agosto de dois mil e quatorze, com o objetivo de iniciar a coleta de dados.

Etapa 3: Realização de contato com as escolas, com o objetivo de explicitar a intenção da pesquisa, os profissionais participantes e as finalidades do questionário.

Etapa 4: Envio dos Termos de Consentimento Livre e Esclarecido para os participantes da pesquisa e recebimento com a assinatura dos mesmos, tendo em vista a concordância em participar da pesquisa.

Etapa 5: Envio dos questionários, via e-mail, para as doze escolas, com o objetivo de verificar os projetos de ensino e de aprendizagem multi, trans e interdisciplinares que foram, estão sendo desenvolvidos e encontram-se em fase de planejamento no ensino fundamental dessas escolas.

Etapa 6: Devolutiva dos questionários das escolas, via e-mail.

Etapa 7: Tabulação e organização dos dados coletados por meio dos questionários em quadros de análise.

Etapa 8: Acompanhamento in loco dos projetos e das atividades desenvolvidas na Escola Básica Municipal Irmão Miguel, localizada em Concórdia. Esse acompanhamento consistiu em observar, recolher e analisar documentos comprobatórios dos projetos e atividades planejadas, tais como planos de ensino, registro das atividades e conversa com os professores, tendo em vista verificar o que a escola realiza e como organiza suas atividades voltadas para o projeto do Obeduc.

As etapas mencionadas foram realizadas até o momento, porém outras ações irão se efetivar, dentre elas o envio à Escola Básica Municipal Irmão Miguel de um segundo questionário, particularmente, aos cinco profissionais que o responderam por ocasião de sua primeira aplicação, tendo em vista a coleta de dados a respeito dos dilemas, dificuldades e desafios na implementação de projetos de ensino e de aprendizagem multi, trans e interdisciplinares.

\section{Procedimento para análise dos dados}

Para análise dos dados efetuar-se-á a análise de conteúdo das respostas dos sujeitos participantes.

Bardin (1977, p. 95) organiza a análise de conteúdo em fases e, consequentemente, em torno de três polos cronológicos, sendo eles "a pré-análise, a exploração do material e o tratamento dos resultados, a inferência e interpretação”. A pré-análise consiste em esquematizar a análise a ser realizada, com procedimentos definidos, porém flexíveis. A exploração do material consiste em efetivar a etapa anterior. E, o tratamento dos resultados, a inferência e interpretação objetivam analisar os resultados obtidos para que se tornem válidos e significativos.

A partir dos objetivos da pesquisa foram organizadas algumas categorias de análise, a saber:

Categoria A) Projetos de ensino e de aprendizagem multi, trans e interdisciplinares desenvolvidos no ensino fundamental da escola pública municipal localizada em Concórdia: finalidade de sua organização, os sujeitos participantes, o período de realização, a metodologia utilizada, as principais atividades desenvolvidas e a avaliação dos mesmos.

As questões com os elementos que contribuíram para responder ao objetivo desta categoria foram as questões A, B, C, D, E, F, G e H encontradas nos questionários para diretores e coordenadores. E, as questões E, F, G e $\mathrm{K}$, do questionário para profesores.

Categoria B) Dilemas, dificuldades ou obstáculos que os participantes do percurso de planejamento e de execução do projeto de ensino e de aprendizagem multi, trans ou interdisciplinar, da Escola de Concórdia, selecionada para constituir foco de observação e análise desta pesquisa, evidenciaram neste percurso.

As questões com os elementos que contribuíram para responder ao objetivo desta categoria foram as questões I, J e K do questionário para diretores e coordenadores, e B, J e M do questionário para profesores.

Durante o acompanhamento observou-se as ações desenvolvidas, analisou-se os planos de trabalho dos professores, os planos de aula e registrou-se, por meio de fotografias, as atividades desenvolvidas. Após a aplicação do questionário que compõem a segunda parte da pesquisa, serão utilizados alguns elementos das questões para também responder ao objetivo desta categoria.

\section{Resultados}

Será apresentado somente uma parte da análise dos dados da Categoria A, especificamente a motivação e finalidades buscadas no projeto em desenvolvimento na Escola Básica Municipal Irmão Miguel, identificada como Escola A.

Localizada no município de Concórdia/SC, a Escola A é uma instituição pública mantida pela Secretaria Municipal de Educação deste municipio. Possui os níveis de Educação Infantil e Ensino Fundamental, totalizando um atendimento de aproximadamente trezentos e setenta alunos.

Com relação à motivação e finalidades buscadas no projeto que a escola já desenvolveu e vem desenvolvendo, justificam-se por ser uma maneira significativa de se trabalhar os aspectos pedagógicos. Ou seja, segundo $\mathrm{C} 1$, tais projetos justificam-se pelo fato de "trabalhar de uma forma mais significativa, fazendo com que o aluno percebesse a relação entre as disciplinas. Despertar mais o interesse ao estudo, uma 
vez que os temas, conhecimentos abordados são de vivência do aluno".

Todos os profissionais da escola envolveram-se e envolvem-se na realização dos projetos. Como relatou C1 "começamos com os professores das séries finais, o trabalho foi acontecendo e envolvendo a todos, séries iniciais, educação infantil, alunos de inclusão (sala multifuncional), auxiliar de biblioteca, secretaria, orientadora, gestor".

Ao encontro desse maior envolvimento, tendo em vista o avanço na direção da integração entre os saberes, Neto (2013) faz a seguinte comparação:

Imaginemos que sejamos um grupo de aventureiros querendo adentrar numa mata fechada. Sabemos que vamos enfrentar dificuldades, mas temos que enfrentar nossos medos e ir em frente. A partir do momento que começarmos a caminhar através desta mata não voltaremos mais a sermos o que éramos antes. É um caminho sem volta, mas se o grupo estiver coeso e com um propósito bem firme, os problemas que surgirão serão bem encaminhados e solucionados [...] interatividade, agilidade, complexidade, dentre outros aspectos, podem ser considerados a "mata fechada" moderna [...] os professores são os proponentes, os guias da viagem através da mata fechada do conhecimento. Não é a vontade ou a garra do "guia” que será determinante nesta imersão ao conhecimento. Mas é a contribuição que cada um dos participantes do grupo dará que levará ao sucesso, ou não, desta viagem.

Observa-se que, na Escola A, o grupo de aventureiros composto pelos professores e demais profissionais estão adentrando nesta mata fechada do conhecimento, e para isso, cada guia vem contribuindo para o andamento positivo da viagem, apesar dos dilemas e das dificuldades.

Em 2015, a Escola A está desenvolvendo sua proposta multidisciplinar vinculada ao Projeto do Observatório da Educação da Universidade do Oeste de Santa Catarina (Unoesc), a qual versa sobre “A relação interpessoal na diversidade social, cultural e econômica e suas implicações na educação" e objetiva promover melhoria nas relações interpessoais que venham contribuir para construção do conhecimento e suas implicações na realidade social em que a unidade escolar está inserida.

Como esta instituição organiza-se por trimestres, os temas ou elementos sociais elencados foram Saúde $\left(1^{\circ}\right.$ trimestre), Economia ( $2^{\circ}$ trimestre) e Meio Ambiente ( $3^{\circ}$ trimestre).

De modo geral, analisou-se que, pelo fato do planejamento na Escola A acontecer de maneira individual, é possível caracterizar tais propostas como multidisciplinares. Além disso, cada disciplina também avaliou individualmente a aprendizagem dos alunos.

Isso vai ao encontro da definição de multidisciplinaridade por Japíassu (1976, apud NETO, 2013), pois cita que a mesma “[...] consiste em estudar um objeto sob diferentes ângulos, mas sem que tenha necessariamente havido um acordo prévio sobre os métodos a seguir ou sobre os conceitos a serem utilizados”. Nesse caso, algumas disciplinas abordaram os elementos sociais de uma determinada forma, e, consequentemente, formulou determinados objetivos com diferentes maneiras de avaliação.

Porém, com o desenrolar da proposta, principalmente quando o quadro de docentes se completou devido ao fato de grande parte deles ser Admitido em Caráter Temporário (ACT), além de que outras formações continuadas foram realizadas neste período, constatouse que alguns professores começaram a planejar algumas atividades de maneira coletiva.

Além disso, a professora P3, regente da turma do quinto ano, também planejou e desenvolveu um trabalho enaltecendo o diálogo entre as áreas do conhecimento. Neste caso, considerando os temas "entulho", “poluição”, “alcoolismo”, “água parada”, “lixo”, "armazenamento de alimentos” e "cigarro", envolveu as disciplinas de Ciências, Português, História, Geografia, Ensino Religioso e Matemática, como pode-se observar na Figura 1.

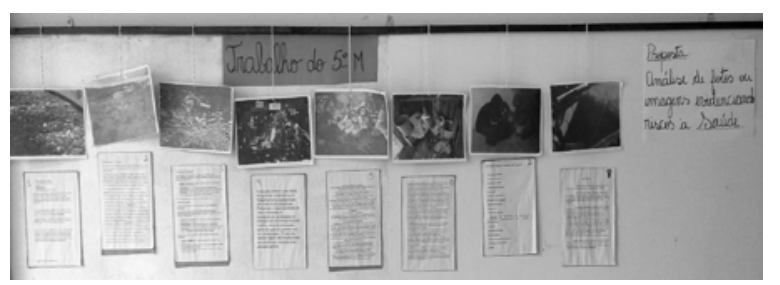

Figura 1: Exposição dos trabalhos realizados pelo $5^{\circ}$ ano envolvendo o elemento social "saúde"

Neste percurso, verificou-se que os temas se vincularam à vida pessoal de cada aluno, tornando-se significativos ou pertinentes pelo fato de em algumas famílias existir casos envolvendo os temas trabalhados.

Como afirma Morin (2013) "é a contextualização que sempre torna possível o conhecimento pertinente. [...] O conhecimento pertinente tenta situar as informações num contexto global e, se possível, num contexto geográfico, histórico”.

Dessa maneira, essa interação entre os saberes proporcionou um conhecimento global da temática, pois, caso contrário, como afirma Morin (2013) “o ensino realizado por meio de disciplinas fechadas nelas mesmas atrofia a atitude natural do espírito para situar e contextualizar”.

Também, tendo em vista o desenvolvimento desta atividade numa tentativa interdisciplinar, a professora P3 salientou a importância de se oportunizar mais tempo e espaço para o planejamento coletivo, pois assim poder-se-ia dialogar com as disciplinas de Educação Física, Literatura dramatizada, Xadrez, Espanhol e Arte. Dessa maneira, como afirma Severino (1995) "tanto quanto o agir, também o saber não pode se dar na fragmentação: precisa acontecer sob a perspectiva da totalidade”.

\section{Discussão}

Espera-se que os resultados dessa pesquisa contribuam na e para a melhoria qualitativa da educação oferecida pelas instituições vinculadas ao projeto do OBEDUC, sendo isso possível por meio da desconstrução de práticas pedagógicas fragmentadas e 
descontextualizadas, pensando na adoção e na incorporação de atitudes interdisciplinares e transdisciplinares, já que estas possuem uma visão global tanto do ser humano quanto do ensino, considerando ambos em seus múltiplos aspectos.

Considerando a proposta da Escola A anteriormente citada, analisa-se que, por mais que de modo geral a mesma caracteriza-se como multidisciplinar, há algumas tentativas interdisciplinares permeando e orientando a prática pedagógica de alguns professores e professoras.

Com relação à prática da interdisciplinaridade no contexto da sala de aula, Lück (2013) afirma que a mesma "[...] implica vivência do espírito de parceria, de integração entre teoria e prática, conteúdo e realidade, objetividade e subjetividade, ensino e avaliação, meios e fins, tempo e espaço, professor e aluno, reflexão e ação, dentre muitos dos múltiplos fatores interagentes do processo pedagógico".

Nas ações pedagógicas da Escola A também se observou, principalmente, essa relação entre conteúdo e realidade, tanto no planejamento quanto na prática, condizendo, desse modo, com tal prática interdisciplinar.

Como cita Etges (1995) “o mundo do vivido, do analógico, do imediato são contextos que a atividade interdisciplinar precisa atingir, para dissolvê-los e transformá-los em estruturas de pensamento, de ciência, de conhecimento".

E, voltando-se especificamente para a prática pedagógica desenvolvida pela professora P3, é possível destacar as ideias de Jantsch e Bianchetti (1995), quando afirmam que "a ideia de que somente é possível ser interdisciplinar em grupo, contrapomos a de que a sós também é possível. Um grupo pode ser mais homogêneo e superficial que o indivíduo que busca recursos de várias ciências para explicar determinado processo". Em outras palavras, por mais que a prática pedagógica da professora P3 se deu de modo individual, também pode ser considerada interdisciplinar, já que nos anos iniciais vários conhecimentos e áreas do saber (português, matemática, ciências, geografia, história, entre outras) são abordados pelo professor regente, diferentemente dos anos finais, no qual se constata maior fragmentação.

\section{Referencias}

ANTÔNIO, S. (2002). Educação $e$
Transdisciplinaridade: crise e reencantamento da
aprendizagem. Rio de Janeiro: Lucerna.

BARDIN, L. (1977). Análise de conteúdo. Lisboa: Edições 70.

DESCARTES, R. (2004). Discurso do método. São Paulo: Nova Cultural.

ETGES, N. J. (1995). Ciência, interdisciplinaridade e educação. En JANTSCH, A. P., BIANCHETTI, L. (Orgs.). Interdisciplinaridade: para além da filosofia do sujeito (pp. 51-84). Petrópolis: Vozes.

FOLLMANN, J. I. (2005). A segmentação do conhecimento é um fruto perverso da modernidade. Revista IHU ON-LINE. Año 5, p. 8-12. http://www.ihuonline.unisinos.br/media/pdf/IHUOnli neEdicao153.pdf

GIL, A. C. (2002). Como elaborar projetos de pesquisa. São Paulo: Atlas.

JANTSCH, A. P., BIANCHETTI, L. (1995). Interdisciplinaridade: para além da filosofia do sujeito. Petrópolis: Vozes.

LÜCK, H. (2013). Pedagogia interdisciplinar: fundamentos teórico-metodológicos. Petrópolis: Vozes.

MORIN, E. (2003). A cabeça bem feita: repensar a reforma, reformar o pensamento. Rio de Janeiro: Bertrand Brasil.

MORIN, E. (2013). Educação e Complexidade: os sete saberes e outros ensaios. En ALMEIDA, M. C.; CARVALHO, E. A. (Orgs.). (pp. 83-109). São Paulo: Cortez.

NETO, O. I. R. (2013). Interdisciplinaridade escolar: um caminho possível. Tese de Doutorado, Universidade Federal do Rio Grande do Sul, Porto Alegre, Brasil. http://www.lume.ufrgs.br/bitstream/handle/10183/787 71/000898727.pdf?sequence $=1$

SANTOS, A. (2009). Complexidade e Transdisciplinaridade em Educação: Cinco princípios para resgatar o elo perdido. En SANTOS, A., SOMMERMAN, A. (Orgs.). Complexidade $e$ transdisciplinaridade: em busca da totalidade perdida. Conceitos e práticas na educação. (pp. 1538). Porto Alegre: Sulina.

SEVERINO, A. J. (1995). O uno e o múltiplo: o sentido antropológico do interdisciplinar. En JANTSCH, A. P., BIANCHETTI, L. (Orgs.). Interdisciplinaridade: para além da filosofia do sujeito. (pp. 150-175). Petrópolis: Vozes.

SOMMERMAN, A. (2005). Inter ou transdisciplinaridade? Da fragmentação disciplinar ao novo diálogo entre os saberes. São Paulo: CETRANS. 